\title{
Competitive Association of Antibiotics with a Clay Mineral and Organoclay Derivatives as a Control of Their Lifetimes in the Environment
}

Tiago De Oliveira, ${ }^{\dagger}$ Elodie Fernandez, ${ }^{\dagger}$ Laëtitia Fougère, ${ }^{\ddagger}$ Emilie Destandau, ${ }^{\ddagger}$ Mohammed Boussafir, ${ }^{\dagger}$

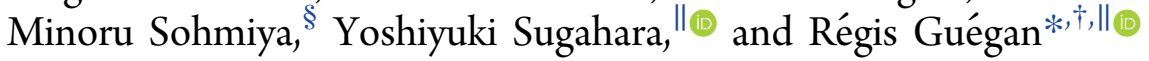

${ }^{\dagger}$ Institut des Sciences de la Terre d'Orléans, UMR 7327, CNRS-Université d'Orléans, 1A Rue de la Férollerie, 45071 Orléans Cedex 2, France

${ }^{\ddagger}$ Institut de Chimie Organique et Analytique, UMR 7311, CNRS-Université d'Orléans, Rue de Chartres, 45067 Orléans Cedex 2 , France

${ }^{\S}$ Department of Materials and Life Science, Faculty of Science and Technology, Seikei University, 3-3-1 Kichijojikitamachi, Musashino-shi, Tokyo 180-8633, Japan

${ }^{\|}$Faculty of Science and Engineering, (Global Center for Science and Engineering), Waseda University, 3-4-1 Okubo, Shinjuku-ku, Tokyo 169-8555, Japan

\section{Supporting Information}

ABSTRACT: A Na-smectite clay mineral (Na-Mt) was exchanged with two concentrations of benzyldimethyltetradecyl ammonium chloride cationic surfactant up to one time the cation exchange capacity. Nonionic organoclay was prepared with polyoxyethylene (20) oleyl ether (Brij-O20) nonionic surfactant at one concentration. The resulting organoclays displayed lateral layer organization of the surfactants within their interlayer space.. The adsorption properties of these organoclays and the starting raw clay mineral were evaluated for three extensively used antibiotic pharmaceutical products: the amoxicillin (AMX), the sulfamethoxazole (SMX), and the trimethoprim (TRI), recognized as recalcitrant compounds to conventional water treatments and to display a complex behavior for different $\mathrm{pH}$ and temperature experimental conditions. Besides showing short half-life time with possible degradation by UV radiation, these antibiotics associated with mineral phases cause serious environmental issues of which the toxic effect can be exacerbated in the presence of other chemical compounds. From the set of data obtained by complementary techniques: UV and Fourier transform infrared spectroscopy, high-performance liquid chromatography coupled with mass spectrometry, and X-ray diffraction, it appears that the nonionic organoclay shows its versatility for the adsorption of individual molecules as well as a pool of antibiotics. The mixing of the three antibiotics showing different electric charged species (cations, anions, and zwitterions) mimics the natural context drives to a deep modification of the adsorption behavior onto the different materials that can act as possible carrier mineral phases in aquatic environment. These competition effects can be measured through the significant decrease of the $K_{\mathrm{F}}$ Freundlich constants for AMX in the presence of other molecules (or electrolytes), whereas TRI and SMX, by their possible association, create a synergistic effect that favors their adsorption on the whole layered materials.

\section{INTRODUCTION}

In 1928, the discovery of penicillin by Alexander Fleming opened the way to antibiotics treatment in modern pharmacopoeia and it took about 15 years in the end of the Second World War, for their prescription being actually endorsed. If their therapeutic efficiency does not need to be demonstrated, their overuse is increasingly criticized for several reasons: (i) the fate of antibiotics or their metabolites associated with mineral phases in aquatic environments leading to toxic effects on several ecosystems; ${ }^{1-5}$ (ii) an insidious food contamination with an accumulation of antibiotics or pool of bioactive molecules in human biological tissues leading to a potential reduction in their therapeutic efficiency; ${ }^{4}$ and (iii) the threat of an antibiotics resistance with the emergence of superbacteria without any unavailable current solution interpellating both the scientific community and the public authorities. Amoxicillin (AMX), sulfamethoxazole (SMX), and trimethoprim (TRI), with their high consumption and

Received: August 15, 2018

Accepted: October 25, 2018

Published: November 12, 2018 


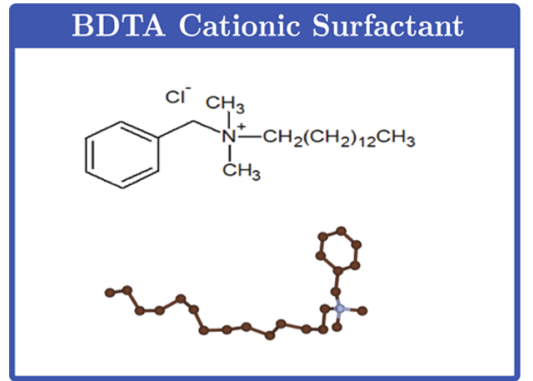

Brij-O-20 Nonionic Surfactant

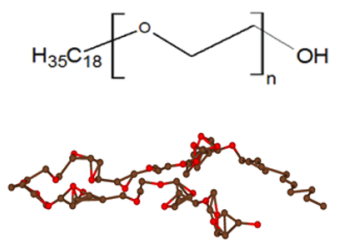

Figure 1. BDTA cationic and Brij nonionic surfactants used in this study as chemical modifiers for the preparation of the organoclays.

versatility to treat multiple pathologies, are frequently found at concentrations up to microgram per liter in natural and wastewaters (typically in the range of $0.6-2 \mu \mathrm{g} \mathrm{L} \mathrm{L}^{-1}$ ) and even in soils, leading to serious environmental issues. ${ }^{1-3,5-18}$

The presence of pharmaceuticals (PhACs) even at low concentration is now recognized to have significant toxic actions on numerous ecosystems with the alteration of both the activity and boldness of several fishes. ${ }^{3-20}$ Moreover, because fish tissues show high concentration in both organic micropollutants and trace elements, they drive to the contamination of the whole trophic chain. Conversely, some benthic invertebrate communities can be eradicated with exposure to contaminated sediments or/and PhAC. Thus, understanding of both the dynamics of PhACs and their association with mineral phases in the environment is of first importance to apprehend their pollution in water resources and toxic actions on various ecosystems. Although the antibiotics in this study (at least the mobilized fraction) display a moderate short half-life time (up to couple hours), their presence in aquatic environments, even as short as possible, represent a possible pathway for bacterial antibioresistance because of their fast life cycle (on average, a generation is obtained for each $20 \mathrm{~min}$ ).

In aquatic environments, organic compounds including pollutants are frequently associated or in close interaction with mineral phases in suspension, leading to a possible preservation and thus a persistence in aquatic environment. ${ }^{1,3,7,13,19-21}$ Among the mineral phases found in effluents, clay minerals or/and their organoclay derivatives (assimilated or model humic clay complexes) represent a large fraction which were recognized to play a role in the preservation of the organic matter. These layered materials show a large specific surface area, ion-exchange capacities, and outstanding hydration properties, leading to an exfoliation of the nanosheets that can even self-assemble in liquid crystalline phases. ${ }^{22-26}$ Their association as holding or carrier mineral phases with pharmaceuticals and other pollutants represents a possible vector of diffusion acting as a potential "time bomb" of pollution, with an easy release or remobilization of the pollutants after a change of the environmental conditions $(\mathrm{pH}$, temperature, or electrolytes) along effluents.

Thus, understanding of the adsorption mechanisms or the main driving force leading to adsorption, as well as the competition of a pool of antibiotics onto clay mineral and its organoclay derivatives, is of first importance to figure out the mobility and fate of organic pollutants in the environment. This study also tackles the possible uses of organoclays as novel adsorbents used in water treatments. Indeed, organoclays, prepared through the chemical modification of a clay mineral surface with both cationic and nonionic surfactants, were suggested as realistic materials in water remediation strategies with regards to their singular adsorption properties for several pollutants. $7,9,11,14,17,20,21,23,24,27$ Nevertheless, the final properties of organoclays mainly depend on both the nature of the surfactant and its density or arrangement, where nonionic organoclays (i.e., prepared with nonionic surfactants) appear as a polyvalent material for numerous compounds and recently pharmaceuticals.

In that frame research work, this study focuses on the adsorption of three antibiotics: the AMX, the SMX, and TRI, showing different functional groups and electric charge onto four adsorbent materials: a starting reference montmorillonite and three organoclays as mimic humic-clay complexes. The organoclays were prepared with cationic: the benzyldimethyltetradecyl ammonium (BDTA) and nonionic: the polyoxyethylene (20) oleyl ether (Brij-O20) surfactants at two different molecular arrangements and densities/loadings, allowing us to modulate both the hydrophocity/hydrophilicity ratio and their ion-exchange capacity. Through the use of a set of complementary techniques [UV spectroscopy, highperformance liquid chromatography coupled with mass spectrometry (HPLC/MS), Fourier transform infrared (FTIR) spectroscopy, and X-ray diffraction (XRD)], this study gives important insights into the understanding of the interaction mechanisms controlling the adsorption of a pool of antibiotics in different experimental conditions for a proper simulation of the fate of these antibiotics associated with mineral phases/humic clay complexes in a natural context.

\section{MATERIALS AND METHODS}

2.1. Materials. Wyoming sodium montmorillonite (Mt), obtained from the Source Clay Minerals Repository, University of Missouri (Columbia, MO), was used in this study as a starting material. The structural formula can be expressed as: $\left(\mathrm{Ca}_{0.12} \mathrm{Na}_{0.32} \mathrm{~K}_{0.05}\right)\left[\mathrm{Al}_{3.01} \mathrm{Fe}(\mathrm{III})_{0.41} \mathrm{Mn}_{0.01} \mathrm{Mg}_{0.54} \mathrm{Ti}_{0.02}\right]$ $\left[\mathrm{Si}_{7,98} \mathrm{Al}_{0.02}\right] \mathrm{O}_{20}(\mathrm{OH})_{4}$. Mt was fractioned to $<2 \mu \mathrm{m}$ by gravity sedimentation, purified, and sodium $\left(\mathrm{Na}^{+}\right)$exchanged. This $\mathrm{Mt}$ clay mineral shows a cation exchange capacity (CEC) of 76.4 mequiv per 100 g clay.

BDTA cationic and polyoxyethylene (20) oleyl ether (BrijO20) nonionic surfactants (Figure 1) were supplied from Sigma-Aldrich Chemical. Aqueous solutions of surfactants with Millipore deionized water $(25 \mathrm{~mL})$ were prepared at room temperature $\left(25^{\circ} \mathrm{C}\right)$ at concentrations of 0.4 and 1 time the CEC of Mt clay for BDTA and at a concentration of about $1.13 \times 10^{-3} \mathrm{~mol} \mathrm{~L}^{-1}$ for Brij-O20. Then, these surfactant solutions were mixed to $\mathrm{Mt}$ aqueous dispersions $(25 \mathrm{~mL}$ with $100 \mathrm{mg}$ of Mt clay) before being stirred at $300 \mathrm{rpm}$ for $24 \mathrm{~h}$. At the end of this procedure, the solutions were centrifuged at $3000 \mathrm{rpm}$ for $20 \mathrm{~min}$ and the supernatants were removed and 
the solid fractions (organoclays) were recovered. The resulting organoclays were dried at $100{ }^{\circ} \mathrm{C}$ for $24 \mathrm{~h}$ before analysis without altering the confined organic compounds by thermal analyses.

2.2. Experimental Techniques. The concentration of the three antibiotics before and after being in contact with the layered adsorbents: raw clay mineral and organoclays was obtained by UV-visible analysis using an Evolution 220 spectrophotometer (Thermo Scientific). FTIR measurements in the range $650-4000 \mathrm{~cm}^{-1}$ were recorded using a Thermo Nicolet 6700 FT spectrometer equipped with a deuterated triglycine sulfate detector and a Nicolet Continuum microscope. The powder samples were spread over a $\mathrm{NaCl}$ window of the microscope. The analyzed sample area was a square of side $100 \mu \mathrm{m}$ chosen under the microscope $15 \times$ Infinity Reflechromat objective. The analyses were performed in transmission mode, and each spectrum corresponded to the average of 256 scans was collected at $2 \mathrm{~cm}^{-1}$ resolution. The $d_{001}$ spacing's of the layered materials before and after being in contact with the antibiotics were determined by the first $00 l$ reflection from the X-ray patterns which were recorded in a conventional $\theta-\theta$ Bragg-Brentano configuration by using a Thermo Electron ARLX'TRA diffractometer equipped with a $\mathrm{Cu}$ anode $(\mathrm{Cu} \mathrm{K} \alpha=1.5418 \AA$ ) coupled with a $\mathrm{Si}(\mathrm{Li})$ solid detector. The diffractograms on dry samples $\left(100{ }^{\circ} \mathrm{C}\right.$ for $24 \mathrm{~h}$ ) were performed between $1^{\circ}$ and $24^{\circ}(2 \theta)$ with angular and time steps of $0.04^{\circ}$ and $10 \mathrm{~s}$, respectively.

Chromatographic separation was achieved with an Ultimate 3000 RSLC (Thermo Fisher Scientific Inc., CA, USA) liquid chromatography system equipped with a binary pump and a Nucleodur C18 Gravity column $(150 \mathrm{~mm} \times 2 \mathrm{~mm} ; 1.8 \mu \mathrm{m}$, Macherey-Nagel) supplemented by a guard column. Separation was performed at a flow rate of $0.4 \mathrm{~mL} \mathrm{~min}^{-1}$, and the temperature was maintained at $30{ }^{\circ} \mathrm{C}$. Two solvents were used as the mobile phase: ultrapure water (solvent A) and ACN (solvent B) both acidified with $0.1 \%$ of formic acid. The elution gradient was a transition from $95 \%$ to $5 \%$ of A in 16.2 min followed by $3.3 \mathrm{~min}$ of $100 \%$ of $\mathrm{B}$ and then a return to the initial conditions ( $95 \%$ of A) during $10 \mathrm{~min}$ for a total analysis time of $29 \mathrm{~min}$. The chromatography system was coupled to a TSQ Endura triple quadrupole mass spectrometer equipped with a heated electrospray ionization interface (Thermo Scientific Inc., San Jose, CA, USA). Quantification was performed in UHPLC/MRM MS with an electrospray ionization source operating in a positive mode, with an electrospray voltage of $3600 \mathrm{~V}$, a vaporizer temperature of 450 ${ }^{\circ} \mathrm{C}$, an ion transfer temperature of $325{ }^{\circ} \mathrm{C}$, sheath gas of 50 Arb, auxiliary gas of $20 \mathrm{Arb}$, and sweep gas of 1 Arb.

2.3. Adsorption of PPs. AMX (6-( $p$-hydroxy- $\alpha$ aminophenylacetamido)penicillanic acid), SMX (4-amino- $N$ (5-methyl-3-isoxazolyl))benzenesulfonamide), and TRI (5[(3,4,5-trimethoxyphenyl) methyl]-2,4-pyrimidinediamine), purchased from Sigma-Aldrich Chemical and assumed to have a purity $>98 \%$, were used in batch adsorption experiments onto raw clay mineral and its organoclay derivatives using at least 10 initial aqueous solutions ranging from $10 \mathrm{mg} \mathrm{L}^{-1}$ to $4 \mathrm{~g}$ $\mathrm{L}^{-1}$. AMX displays a $\log P\left(\log K_{\mathrm{ow}}\right)$ of about 0.87 and $2 \mathrm{pK}$ of 3.23 and 7.43, whereas SMX shows a $\mathrm{p} K_{\mathrm{a}}$ couple of 6.16 and 1.97 (respectively, for the strongest acidic and basic forms) that has a $\log P$ of 0.89 and a water solubility of $610 \mathrm{mg} \mathrm{L}^{-1}$ (at $37^{\circ} \mathrm{C}$ ). TRI shows a $\log P$ of 1.28 , and $2 \mathrm{p} K_{\mathrm{a}}$ of 17.33 and 7.16 (respectively, for the strongest acidic and basic forms) has a water solubility of $400 \mathrm{mg} \mathrm{L}^{-1}$ (at $25{ }^{\circ} \mathrm{C}$ ). The solid-to-liquid ratio was kept constant, where $100 \mathrm{mg}$ of sorbents was used for $50 \mathrm{~mL}$ of $\mathrm{PP}$ aqueous solutions in centrifuge tubes, and the $\mathrm{pH}$ was adjusted by $\mathrm{HCl}$ acidic and $\mathrm{NaOH}$ basic solutions at a $\mathrm{pH}$ of 6.5 close to that of effluents. Samples were shaken on a rotary shaker at $50 \mathrm{rpm}$ during $24 \mathrm{~h}$ in order to reach the equilibrium final concentrations and centrifuged at $5000 \mathrm{rpm}$ for $25 \mathrm{~min}$. Both supernatants and sorbents after contact with the PPs were removed and analyzed through UV-visible spectroscopy and for a pool of pharmaceuticals through HPLC-MS. The amount of adsorbed PPs was calculated by the difference between the initial and equilibrium final concentrations that allowed us to determine the equilibrium adsorption isotherms. Prior XRD and FTIR characterizations, the entire resulting organoclays and $\mathrm{Mt}$ after adsorption of the antibiotics were dried at $100{ }^{\circ} \mathrm{C}$ for $48 \mathrm{~h}$.

2.4. Fitting Procedure. The resulting adsorption isotherms of the antibiotics onto organoclays and Mt were fit using the Langmuir model expressed as

$$
q_{\mathrm{e}}=\frac{q_{\max } K_{\mathrm{L}} C_{\mathrm{e}}}{1+K_{\mathrm{L}} C_{\mathrm{e}}}
$$

where $q_{\mathrm{e}}$ is the equilibrium pharmaceutical amount adsorbed on sorbents $\left(\mathrm{mol} \mathrm{g}^{-1}\right), C_{\mathrm{e}}$ is the equilibrium pharmaceutical concentration in the resulting solution $\left(\mathrm{mol} \mathrm{L}^{-1}\right), q_{\max }$ is the maximum adsorption capacity of the sorbents or the carrier organo-mineral phases $\left(\mathrm{mol} \mathrm{g}^{-1}\right)$, and $K_{\mathrm{L}}$ is the Langmuir adsorption constant $\left(\mathrm{L} \mathrm{mol}{ }^{-1}\right)$ which is related to the free energy $\left(\Delta G^{\circ}\right)$ of adsorption by the relation (2)

$$
\Delta G^{\circ}=-R T \ln K_{\mathrm{L}}
$$

Because the adsorption of the surfactant contributes to a change of the chemical nature of the surface and heterogeneity in the distribution of the adsorption sites, a Freundlich model isotherm equation was used. The Freundlich isotherm is an empirical equation to describe heterogeneous systems of which the linear form is

$$
\ln q_{\mathrm{e}}=\ln K_{\mathrm{F}}+\frac{1}{n} \ln C_{\mathrm{e}}
$$

where $K_{\mathrm{F}}\left(\mathrm{L} \mathrm{g}^{-1}\right)$ and $n$ are the Freundlich adsorption isotherm constants, being indicative of the extent of the adsorption and the degree of nonlinearity between the solute concentration and adsorption, respectively.

\section{RESULTS AND DISCUSSION}

3.1. Speciation of the Antibiotics. The selected antibiotics in this study show complex and various functional groups as their therapeutic actions. Indeed, AMX or the SMX exhibits two $\mathrm{p} K_{\mathrm{a}}$ couples leading to cationic-zwitterionicanionic behavior (along the $\mathrm{pH}$ range $0-14$ ) in contrast to the TRI, showing a speciation diagram with only cationic and zwitterionic species (Figure 2). ${ }^{9,28}$ At a $\mathrm{pH}$ close to that of effluents ( $\mathrm{pH}$ at about 6.5 represented as a dashed line in Figure 2), the antibiotics show different electric charges: AMX is mainly zwitterionic (with a speciation frequency at about $90 \%$ ) and anionic (10\%). SMX also displays a similar zwitterionic-anionic behavior with a ratio of $30 / 70 \%$, whereas TRI principally is mainly a cation $(80 \%)$ but shows some zwitterionic species (20\%) (Figure 2). With approximately the same molecular size and similar hydrophobicity with a $\log P$ spreading out from 0.75 to 1.28 , a change of $\mathrm{pH}$ leading to anionic species for AMX for instance would have consisted to 

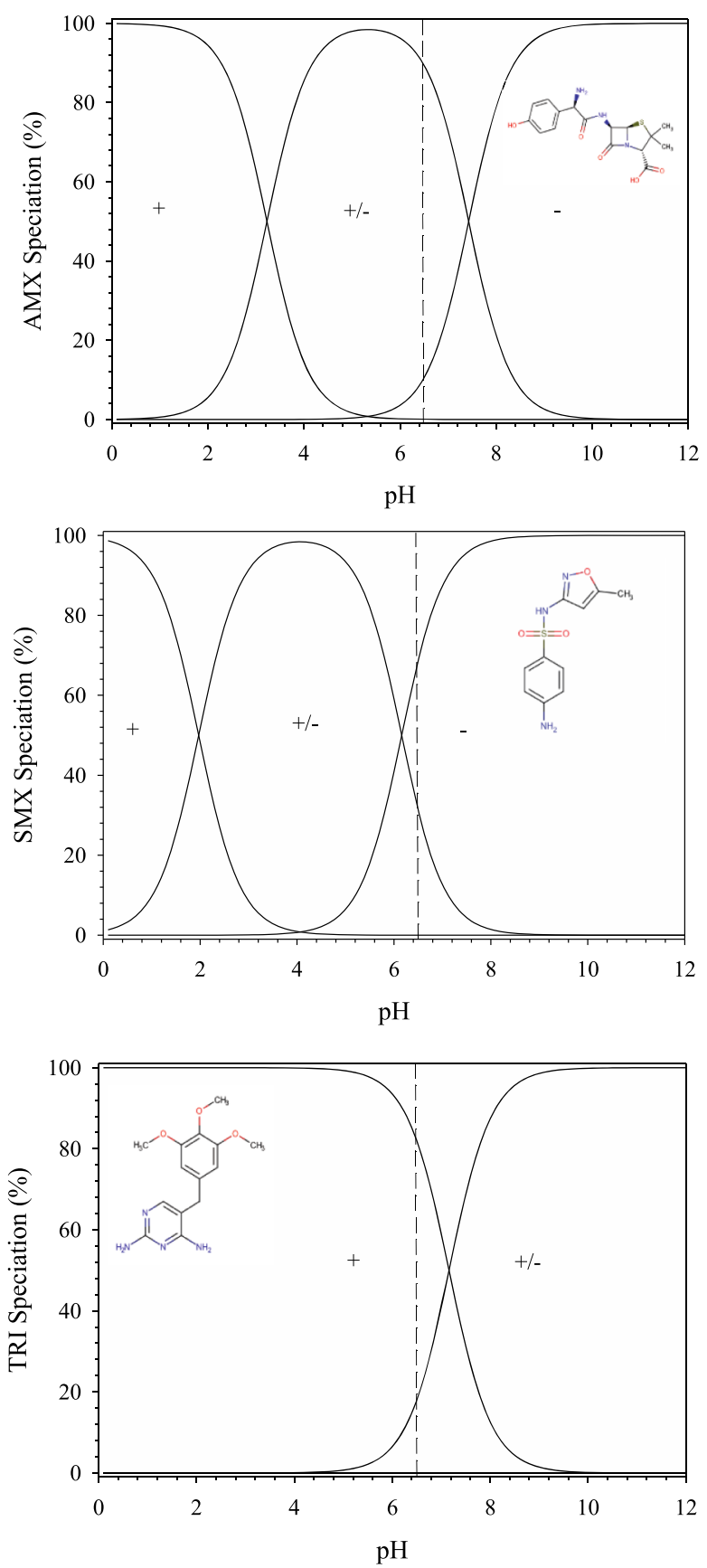

Figure 2. Speciation of the three antibiotics used in this study: AMX, SMX, and TRI, mainly zwitterionic, anionic, and cationic at a $\mathrm{pH}=$ 6.5 , respectively.

get similar observations for SMX or other anionic species about the interactional mechanisms responsible for the formation of complexes with mineral phases. This approach offers the possibility to study the differences in the efficiency of the adsorption without any changes of the experimental conditions (constant $\mathrm{pH}$ and temperature), except the substitution of a chemical. Thus, it justifies a choice to work at only one $\mathrm{pH}$, whereas a complete and deep study in understanding the affinity, on the whole $\mathrm{pH}$ range, of these chemicals onto Na-Mt and the organoclay derivatives, being potential sorbent materials or holding mineral phases in natural environment is needed.
Thus, the pharmaceuticals display for a similar hydrophobicity ( $\log P$ comprised between 0.75 and 1.28) and different electric charges involving interaction mechanisms such as electrotactic interaction (cation exchange or association between organic anions and cationic organoclay), iondipole (with some moieties of the pharmaceuticals and the inorganic cations of the layered materials), and van der Waals interactions (hydrophobic moieties of the antibiotics with those of the environment generated by the intercalated surfactant) as main driving forces for the adsorption onto the layered materials.

3.2. Organoclay Characteristics. On the basis of both XRD with in particular a shift at low angle value of the $00 l$ reflection probing the proper intercalation of the surfactants and FTIR data focusing on the $\mathrm{CH}_{2}$ stretching vibration frequencies of the alkyl chains stressing out the gauche conformation of the molecules (Figures SI-1 and SI-2), the surfactant arrangements can be drawn and summarized as follows in Figure 3: a lateral monolayer $\left(\mathrm{BDTA}_{0.4}-\mathrm{Mt}\right)$ and bilayers (BDTA-Mt and Brij $0.4-\mathrm{Mt}$ ).$^{20-24}$ This offers a large range of materials with versatile and complementary properties: from CEC and hydrophilicity for untreated $\mathrm{Na}-\mathrm{Mt}$, dual hydrophilicity/hydrophobicity for both $\mathrm{BDTA}_{0.4}-\mathrm{Mt}$ and Brij $_{0.4}-\mathrm{Mt}$, to hydrophobicity or organophilicity and an anion adsorption ability for BDTA-Mt, allowing one to expect the adsorption of the antibiotics showing a similar log $P$ but different electric behavior at a $\mathrm{pH}$ of 6.5 (Figure 2).

3.3. Individual Adsorption of the Antibiotics on the Layered Materials. 3.3.1. Adsorption of the AMX. As expected and previously observed for numerous organoclay/ organic product couples, the equilibrium adsorption isotherms confirm the improvement of the adsorption properties of both nonionic and cationic organoclays compared to the raw clay mineral (Figure 2). 9,17,20,21,24 The line shapes of the adsorption isotherms at the equilibrium for the four different layered materials attest the ambivalence of AMX (zwitterionic and anionic forms according to its speciation diagram in Figure 2). The whole adsorption isotherms display a similar evolution with a gradual growth of the adsorbed amount as the equilibrium concentration is increased without the observation of any steady state or plateau underlining the absence of any saturation (Figure 4). Although implying complex and diverse interactional mechanisms due to both the ambivalence of $\mathrm{AMX}^{6,17,28,29}$ and the type of layered materials, the adsorption isotherms allow one to precisely quantify the degree of affinity between AMX and the four adsorbents, where the hydrophobicity appears to contribute in the degree of adsorption. Thus, the BDTA-Mt organoclay seems to be the most efficient material with a maximum adsorbed amount estimated through a Langmuir fit of about $5.68 \times 10^{-3} \mathrm{~mol} \mathrm{~g}^{-1}$, whereas $\mathrm{Brij}_{0.4} \mathrm{Mt}$ shows a value of about $4.44 \times 10^{-3} \mathrm{~mol} \mathrm{~g}^{-1}$ and a maximum amount of $2.40 \times 10^{-3} \mathrm{~mol} \mathrm{~g}^{-1}$ for $\mathrm{BDTA}_{0.4}$ Mt (Table 1$)$. In contrast, Na-Mt adsorbs $9.29 \times 10^{-4} \mathrm{~mol}$ of AMX per gram, 1 order of magnitude lower than the most efficient organoclays, but nevertheless represents an important amount: above the CEC. Zwitterionic compounds such as AMX have been recognized to be easily intercalated and adsorbed in raw clay minerals through ion-dipole forces and cation exchanges. In the case of the organoclays able to solicitate the inorganic cations for a possible exchange (i.e., Brij ${ }_{0.4}-\mathrm{Mt}$ and $\mathrm{BDTA}_{0.4} \mathrm{Mt}$ organoclays), as it was expected with their organophilic behavior as well as the $\log P$ of AMX, additional interactional mechanisms, which however are not reflected in the obtained 


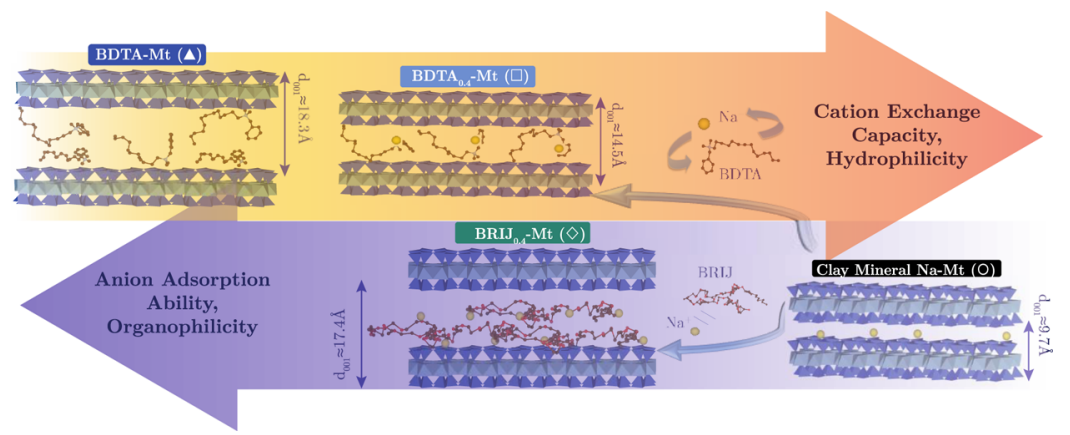

Figure 3. Schematic representation of the whole geo-sorbents used in this study: Na-Mt clay mineral, $\mathrm{BDTA}_{0.4}-\mathrm{Mt}(60 \%$ of the compensating cations is preserved) showing a lateral monolayer arrangement, BDTA-Mt (100\% of the compensation cations is substituted to BDTA) with a lateral bilayer organization, and $\mathrm{Brij}_{0.4} \mathrm{-Mt}$, a nonionic organoclay showing a dual hydrophilic-hydrophobic behavior (where the inorganic cations are kept within the interlayer space). The sorbents used in this study display singular adsorption properties: hydrophobicity/hydrophilicity, cation/ anion retention which will be highlighted with three antibiotics of different chemical natures.

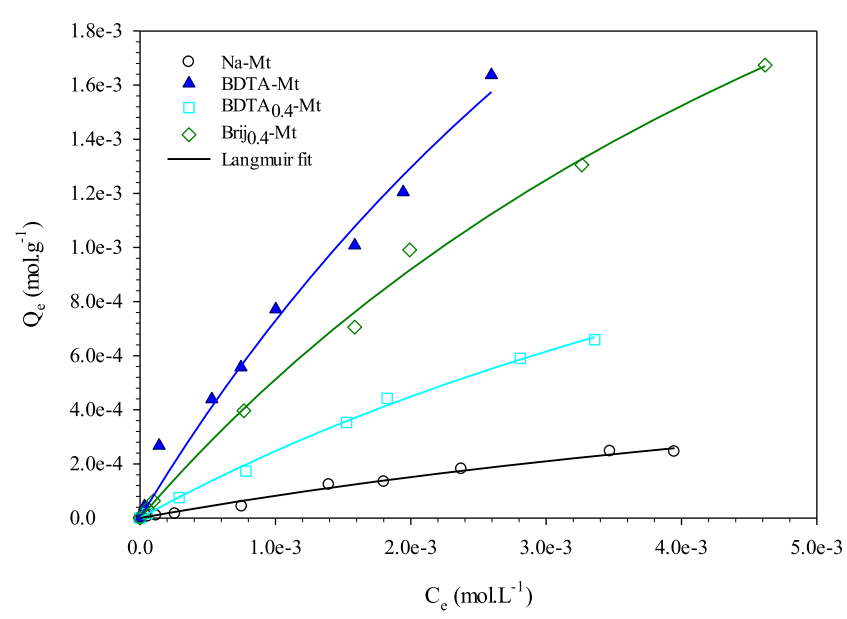

Figure 4. Equilibrium adsorption isotherms of amoxicillin (AMX) onto untreated $\mathrm{Na}$ exchanged montmorillonite: $\mathrm{Na}-\mathrm{Mt}$ (white circle), $\mathrm{BDTA}_{0.4}$-Mt (white-filled light blue square), BDTA-Mt (navy blue triangle top) cationic organoclays, and $\mathrm{Brij}_{0.4}$ - Mt (white-filled green diamond) nonionic organoclay. The solid lines represent the fits by using the Langmuir equation model.

fitting parameters, implying probably molecular hydrophobic and $\pi-\pi$ interactions drive and enhance the maximum adsorbed amount of AMX with an efficiency greater than 477 and about $610 \%$ for $\mathrm{Brij}_{0.4}-\mathrm{Mt}$ and BDTA-Mt, respectively, compared to that of Na-Mt. Because of the ambivalence of AMX and the diversity of adsorption properties of the layered materials used in this study, it is rather hard to find a simple relation or correlation about the extent of the adsorption with one of the features of AMX or characteristics of the sorbents. Indeed, BDTA-Mt, the most hydrophobic material in this study, shows an ability to adsorb anionic compounds including pharmaceuticals as recent study stressed out. ${ }^{20,21}$ This is also observed here where the anionic species of AMX are adsorbed and probably intercalated with regards to the adsorbed amount not only through electrostatic interactions but also through molecular interactions as explained for two other organoclays: Brij $_{0.4}-\mathrm{Mt}$ and $\mathrm{BDTA}_{0.4}-\mathrm{Mt}$.

With regards to the extent of the adsorption, it was expected to observe the intercalation of AMX within the interlayer space of the layered materials. Nevertheless, only the X-ray diffractogram of Na-Mt with AMX (Figure 5) clearly shows a shift to a low angle with a $00 l$ reflection observed at about $6.2^{\circ}\left(d_{001} \cong 14.9 \AA\right)$ at a high-concentration regime $(1-1.7 \mathrm{~g}$
$\mathrm{L}^{-1}$ ) confirming its proper intercalation. Thus, AMX enlarges the interlayer space of $\mathrm{Na}-\mathrm{Mt}$ at a value of about $5.5 \AA$, which is however not sufficient to ensure, besides the large adsorbed amount exceeding the maximum value that AMX may occupy the external surface of the layered materials, an increase of the galleries height of the whole organoclays. Thus, although the diffractograms of the whole organoclays after being in contact with AMX do not show any structural changes (i.e., no shift to the low angle of the $00 l$ reflection was observed as shown in Figure 5), the adsorption of AMX leads to a probable intercalation within the interlayer space where numerous available free spots provided by the hydrocarbon chains of surfactants facilitate the adsorption.

The complexity and richness of the interactional mechanisms between AMX and the different layered materials can be highlighted in FTIR spectra of the layered materials before and after the adsorption (Figure 6). Additional vibrational modes attributed to AMX can be observed with some of them shifted in frequency compared to the bulk ones and are superimposed to those relative of the layered materials (Figure SI-2), with however some differences. Indeed, interestingly, $\mathrm{CO}_{2}^{-}$ stretching bands at about $1800 \mathrm{~cm}^{-1}$ vanish for $\mathrm{Na}-\mathrm{Mt}$ where AMX adsorption can be noticed through the $\mathrm{NH}$ deformation vibration modes identified at $1500-1550 \mathrm{~cm}^{-1} .30$ The absence of the $\mathrm{CO}_{2}{ }^{-}$stretching bands likely indicates that these moieties contribute to the adsorption of AMX through ion-dipole interaction or are blocked because of the confinement effect in such 2D geometry within the interlayer space of the layered materials. Similar scenario occurs for the nonionic organoclay, where moreover to $\mathrm{NH}$ stretching vibration at $1520 \mathrm{~cm}^{-1}$, another band at $1700 \mathrm{~cm}^{-1}$ related to both similar $\mathrm{NH}$ deformation (amine) and $\mathrm{CO}$ stretching (ketone) bands confirms the proper adsorption of AMX and may emphasize the versatility of the moieties involved in the adsorption of the pharmaceutical. In the same way, cationic organoclays exhibit $\mathrm{CO}_{2}^{-}$stretching bands at about 1800 $\mathrm{cm}^{-1}$, whereas those related to the $\mathrm{NH}$ and $\mathrm{CH}_{3}$ bands of AMX are hidden. Besides large adsorbed amount, the incorporation of AMX is not sufficient to express a bulk-like signature in the FTIR spectra. This indicates that the adsorption of AMX leads to a partial covering of the surface on well-localized specific adsorption sites of the holding phase without the formation of any bulk-like aggregates. Here, the adsorption of AMX involves multiple interaction mechanisms soliciting different moieties of the pharmaceutical and 
Table 1. Equilibrium Adsorption Isotherm Constants Determined with Langmuir and Freundlich Models Fit for the

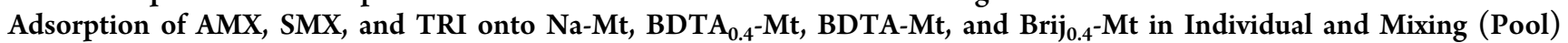
Conditions

\begin{tabular}{|c|c|c|c|c|c|c|c|c|}
\hline \multirow[b]{2}{*}{ adsorbant } & \multirow[b]{2}{*}{ analytes } & \multicolumn{4}{|c|}{ Langmuir } & \multicolumn{3}{|c|}{ Freundlich } \\
\hline & & $q_{\max }\left(\mathrm{mol} \cdot \mathrm{g}^{-1}\right)$ & $K_{\mathrm{L}}\left(\mathrm{L} \cdot \mathrm{mol}^{-1}\right)$ & $\Delta G^{\circ}\left(\mathrm{kJ} \cdot \mathrm{mol}^{-1}\right)$ & $r^{2}$ & $K_{\mathrm{F}}\left(\mathrm{L} \cdot \mathrm{mol}^{-1}\right)$ & $1 / n$ & $r^{2}$ \\
\hline \multirow[t]{2}{*}{ Na-Mt } & AMX & $9.29 \times 10^{-4}$ & $9.73 \times 10^{1}$ & -11.72 & 0.988 & $4.71 \times 10^{-2}$ & 0.94 & 0.984 \\
\hline & pool & $1.46 \times 10^{-4}$ & $2.66 \times 10^{4}$ & -25.79 & 0.947 & $1.60 \times 10^{-2}$ & 0.51 & 0.879 \\
\hline \multirow[t]{2}{*}{ BDTA-Mt } & AMX & $5.68 \times 10^{-3}$ & $1.46 \times 10^{2}$ & -12.76 & 0.972 & $2.07 \times 10^{-1}$ & 0.81 & 0.983 \\
\hline & pool & $1.60 \times 10^{-4}$ & $2.92 \times 10^{4}$ & -26.34 & 0.924 & $2.99 \times 10^{-2}$ & 0.59 & 0.978 \\
\hline $\mathrm{BDTA}_{0.4}-\mathrm{Mt}$ & AMX & $2.40 \times 10^{-3}$ & $1.15 \times 10^{2}$ & -12.15 & 0.997 & $1.22 \times 10^{-1}$ & 0.91 & 0.998 \\
\hline \multirow[t]{2}{*}{$\mathrm{Brij}_{0.4}-\mathrm{Mt}$} & AMX & $4.44 \times 10^{-3}$ & $1.31 \times 10^{2}$ & -12.48 & 0.996 & $2.04 \times 10^{-1}$ & 0.88 & 0.997 \\
\hline & pool & $1.76 \times 10^{-4}$ & $1.01 \times 10^{5}$ & -29.51 & 0.899 & $3.08 \times 10^{-2}$ & 0.55 & 0.828 \\
\hline \multirow[t]{2}{*}{$\mathrm{Na}-\mathrm{Mt}$} & SMX & $2.56 \times 10^{-4}$ & $4.87 \times 10^{2}$ & -15.85 & 0.967 & $1.24 \times 10^{-2}$ & 0.73 & 0.964 \\
\hline & pool & $1.34 \times 10^{-4}$ & $2.69 \times 10^{4}$ & -26.13 & 0.884 & $1.47 \times 10^{-2}$ & 0.55 & 0.996 \\
\hline \multirow[t]{2}{*}{ BDTA-Mt } & SMX & $9.73 \times 10^{-4}$ & $4.78 \times 10^{3}$ & -21.69 & 0.976 & $4.55 \times 10^{-2}$ & 0.59 & 0.961 \\
\hline & pool & $2.06 \times 10^{-4}$ & $4.14 \times 10^{4}$ & -27.23 & 0.952 & $7.85 \times 10^{-2}$ & 0.64 & 0.817 \\
\hline $\mathrm{BDTA}_{0.4}-\mathrm{Mt}$ & SMX & $7.71 \times 10^{-4}$ & $1.41 \times 10^{3}$ & -18.58 & 0.937 & $4.23 \times 10^{-2}$ & 0.67 & 0.967 \\
\hline \multirow[t]{2}{*}{ Brij $_{0.4}-\mathrm{Mt}$} & SMX & $6.97 \times 10^{-4}$ & $5.06 \times 10^{2}$ & -15.95 & 0.976 & $2.43 \times 10^{-2}$ & 0.66 & 0.930 \\
\hline & pool & $1.84 \times 10^{-4}$ & $3.12 \times 10^{4}$ & -26.51 & 0.911 & $1.52 \times 10^{-2}$ & 0.50 & 0.993 \\
\hline \multirow[t]{2}{*}{$\mathrm{Na}-\mathrm{Mt}$} & TRI & $3.80 \times 10^{-4}$ & $5.98 \times 10^{3}$ & -22.27 & 0.982 & $3.44 \times 10^{-3}$ & 0.33 & 0.901 \\
\hline & pool & $1.61 \times 10^{-4}$ & $1.04 \times 10^{5}$ & -29.60 & 0.928 & $6.08 \times 10^{-2}$ & 0.60 & 0.801 \\
\hline \multirow[t]{2}{*}{ BDTA-Mt } & TRI & $2.78 \times 10^{-4}$ & $4.46 \times 10^{3}$ & -21.52 & 0.922 & $2.79 \times 10^{-3}$ & 0.36 & 0.907 \\
\hline & pool & $7.53 \times 10^{-5}$ & $3.67 \times 10^{3}$ & -26.92 & 0.848 & $6.35 \times 10^{-4}$ & 0.27 & 0.725 \\
\hline $\mathrm{BDTA}_{0.4}-\mathrm{Mt}$ & TRI & $3.12 \times 10^{-4}$ & $5.24 \times 10^{3}$ & -21.94 & 0.974 & $3.23 \times 10^{-3}$ & 0.36 & 0.974 \\
\hline \multirow[t]{2}{*}{ Brij $_{0.4}-\mathrm{Mt}$} & TRI & $4.13 \times 10^{-4}$ & $7.59 \times 10^{4}$ & -28.78 & 0.928 & $8.35 \times 10^{-3}$ & 0.40 & 0.996 \\
\hline & pool & $1.93 \times 10^{-4}$ & $1.57 \times 10^{5}$ & -30.64 & 0.868 & $1.38 \times 10^{-1}$ & 0.67 & 0.934 \\
\hline
\end{tabular}

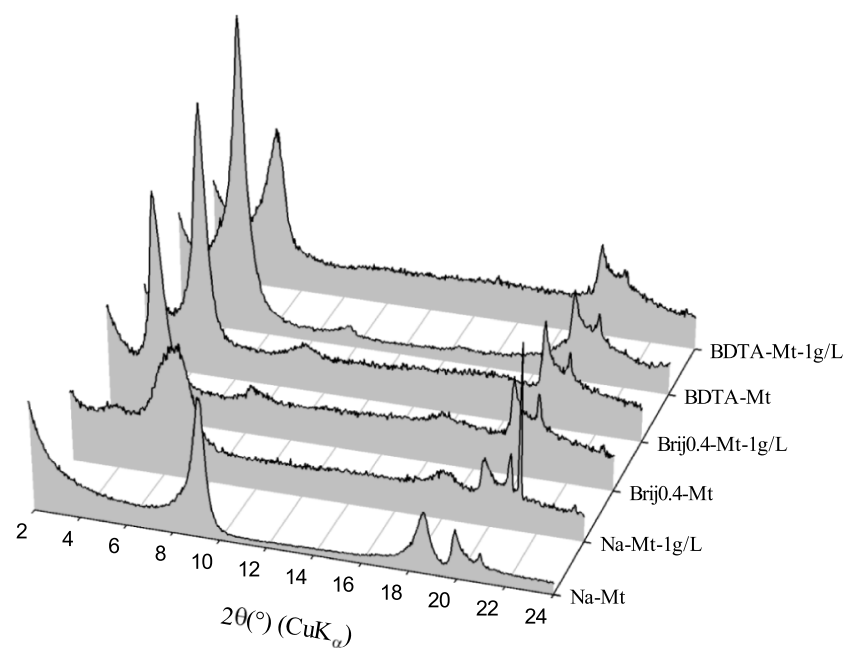

Figure 5. 3D evolution of the XRD patterns of the dehydrated Na-Mt, $\mathrm{Brij}_{0.4}-\mathrm{Mt}$, and BDTA-Mt without and with amoxicillin at a concentration of $1 \mathrm{~g} \mathrm{~L}^{-1}$.

adsorption sites of the holding phases. Those in close interaction with the surface of the layered materials may be drastically affected showing possible broadening and frequency shift of their characteristics bands due to confinement effects and could be even suppressed or hidden due to their close interaction with a clay surface. Thus, FTIR data give important insights into the role of the functional groups leading to the AMX adsorption, where it appears that $\mathrm{NH}$ moieties (i.e., the zwitterionic form of AMX may be privileged in the adsorption) contribute to the intercalation within the interlayer of $\mathrm{Na}-\mathrm{Mt}$ and probably in $\mathrm{BDTA}_{0.4}-\mathrm{Mt}$ and $\mathrm{Brij}_{0.4}$-Mt (identified with the band and shoulder at $\left.1750 \mathrm{~cm}^{-1}\right)$, whereas $\mathrm{CH}_{3}$ stretching bands are not affected. In the case of BDTA-Mt, the excess of positive charge enhances the adsorption of anionic species of

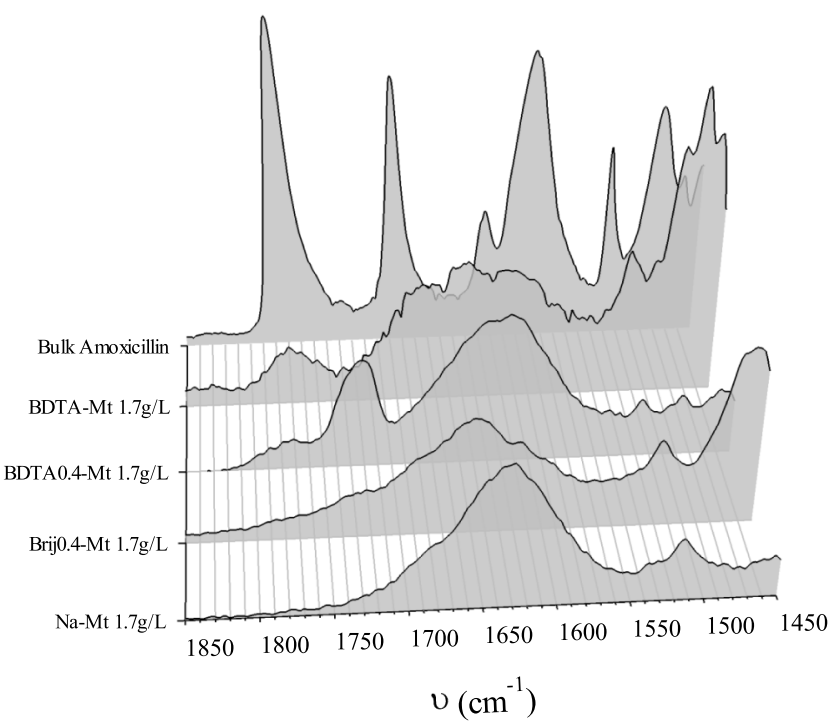

Figure 6. 3D evolution of the FTIR spectra in the $1450-1850 \mathrm{~cm}^{-1}$ wavenumber range (probing the $\mathrm{COO}^{-}$absorption bands) of the layered materials: $\mathrm{Na}-\mathrm{Mt}, \mathrm{BDTA}_{0.4}-\mathrm{Mt}$, BDTA-Mt, and $\mathrm{Brij}_{0.4}-\mathrm{Mt}$ before and after being in contact with AMX at a concentration of $1.7 \mathrm{~g}$ $\mathrm{L}^{-1}$.

AMX probed by the preservation of $\mathrm{CO}_{2}{ }^{-}$stretching bands that may interact with the organic cations $\left(\mathrm{BDTA}^{+}\right)$in addition to possible hydrophobic interaction between the alkyl chains and the organophilic core of AMX.

In addition to give important information in the adsorption processes, this quantitative technique (in the transmission mode) allows one to appreciate the evolution of both surfactants and adsorbed AMX following the adsorption because the intensity of the absorption bands of these compounds is proportional to their density (Figure 7)..$^{20-24}$ 


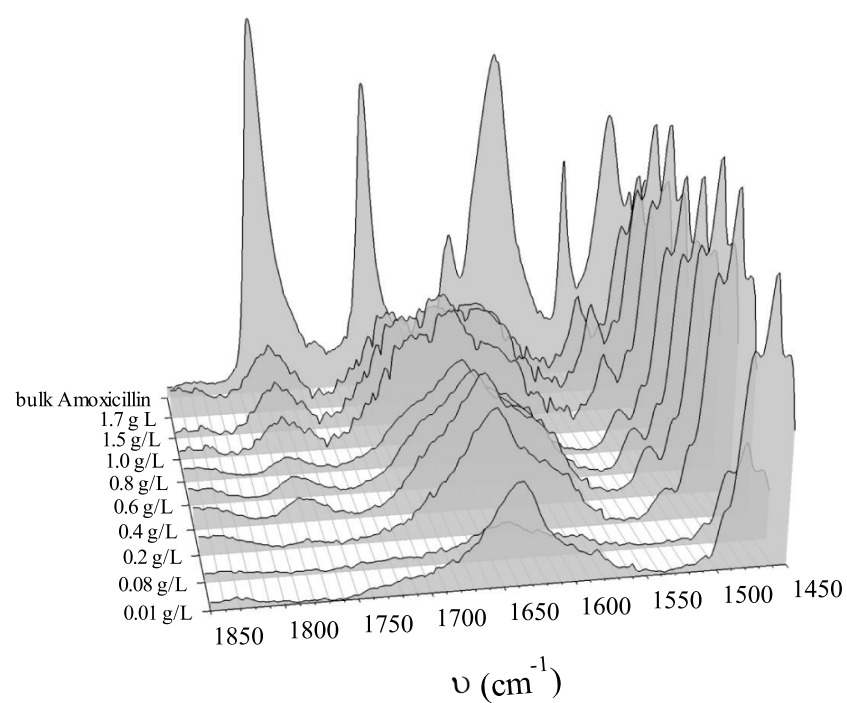

Figure 7. 3D evolution of the FTIR spectra in the $1450-1850 \mathrm{~cm}^{-1}$ wavenumber range (probing the $\mathrm{COO}^{-}$absorption bands) of the BDTA-Mt organoclay (selected series but a similar evolution for the other adsorbents was observed-see the Supporting Information for the evolution on Brij $_{0.4}-\mathrm{Mt}$ ) as a function of the starting amoxicillin concentration $\left(\mathrm{g} \mathrm{L}^{-1}\right)$.

Indeed, the spectral feedbacks of both the $\mathrm{CO}_{2}{ }^{-}$(case of BDTA-Mt) and $\mathrm{NH}$ (case of $\mathrm{Na}-\mathrm{Mt}$ and $\mathrm{Brij}_{0.4}-\mathrm{Mt}$ ) stretching bands follow the starting AMX concentration. The evolution of their integrated intensity $\left(\mathrm{CO}_{2}^{-}\right.$and $\mathrm{NH}$ stretching bands) through a deconvolution process similar to that explained previously shows the same trends as the equilibrium adsorption (Figure 8). However, the line shape differs from a hyperbola which is somehow quite normal and understandable with the use of the starting concentration as $x$ axis. The deconvolution of the $\mathrm{CH}_{2}$ stretching bands stresses out the stability of the organization of both surfactants, whereas the adsorption of AMX within the interlayer space as both FTIR and XRD analyses pointed out.

3.3.2. Adsorption of the SMX. SMX which displays a halflife time of about $10 \mathrm{~h}$ is recognized to not react with soil surfaces including clay minerals while showing a fast mobility in the environment and thus leading to an easy diffusion of its pollution. ${ }^{8,16}$ The probable reasons explaining the absence of any reactions or association with the soil mineral phases may be related to the low $\mathrm{pH}$ value of soils and the hydrophobic character of the pharmaceutical which is now classified as a recalcitrant compound to conventional water treatment. ${ }^{8,16}$ The adsorption isotherms at the equilibrium of SMX follow trends similar to those of AMX onto the four holding phases with a gradual growth of the adsorbed amount as the concentration is increased without reaching any plateau. However, the list of the sorbents differs with the permutation of $\mathrm{Brij}_{0.4}-\mathrm{Mt}$ to $\mathrm{BDTA}_{0.4} \mathrm{Mt}$ with regards to their affinity to SMX which is probably linked to the change of ratio between zwitterionic and anionic species. As expected, at a $\mathrm{pH}$ of about 6.5 for which $67 \%$ SMX species are in an anionic form, the adsorption of this pharmaceutical onto untreated $\mathrm{Na}-\mathrm{Mt}$ is considerably limited and principally involves the zwitterionic form (Figure 9). This leads to a maximum adsorbed amount, estimated through a Langmuir fit with a proper agreement $\left(r^{2}\right.$ $=0.967)$ of about $2.56 \times 10^{-4} \mathrm{~mol} \mathrm{~g}^{-1}$. One may think that this low adsorption results from a lack of hydrophobic
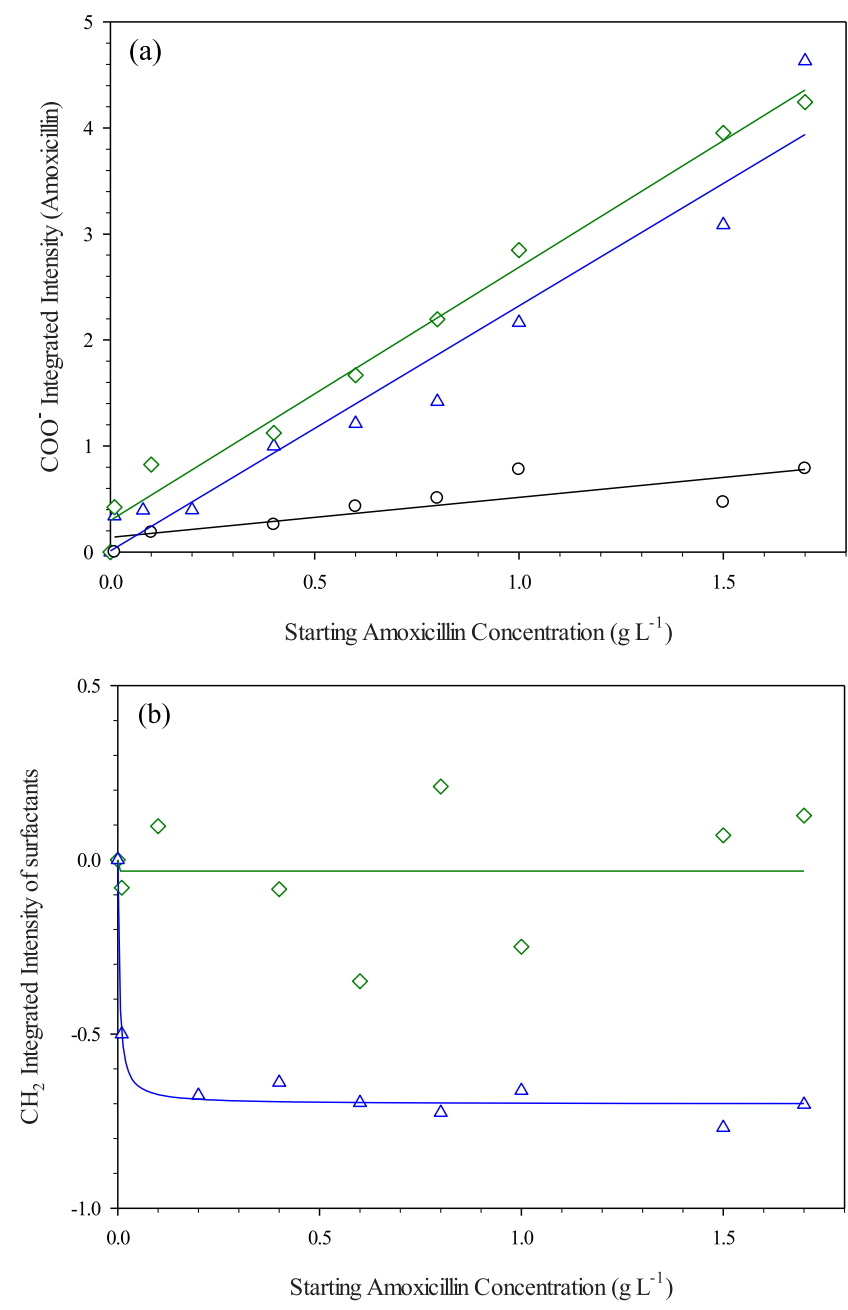

Figure 8. (a) Integrated intensity of the $\mathrm{COO}^{-}$stretching bands of amoxicillin as a function of the starting amoxicillin concentration ( $\mathrm{g}$ $\mathrm{L}^{-1}$ ) for Na-Mt (white circle), BDTA-Mt (navy blue and light gray triangle top) cationic organoclay, and $\mathrm{Brij}_{0.4} \mathrm{-Mt}$ (white-filled green and light gray diamond) nonionic organoclay. (b) Integrated intensity of the $\mathrm{CH}_{2}$ stretching bands of the BDTA and Brij surfactants as a function of the starting amoxicillin concentration $\left(\mathrm{g} \mathrm{L}^{-1}\right)$. The solid lines represent a guide for the eyes.

environment and the presence of repulsive electrostatic interaction involved between the anionic SMX and the negatively surface charges of raw clay mineral, it is however not the case here. Indeed, at high-concentration regime, the total introduced number of moles was about $8 \times 10^{-5} \mathrm{~mol}$ for $100 \mathrm{mg}$ of layered material (i.e., concentration of SMX was about $400 \mathrm{mg} \mathrm{L}^{-1}$ ), where thus $2.67 \times 10^{-5} \mathrm{~mol}$ is in a zwitterionic form, and thus leading to a theoretical maximum value of $2.67 \times 10^{-4} \mathrm{~mol} \mathrm{~g}^{-1}$. The difference between the experimental and expected values represents less than $4 \%$, suggesting that in the case of $\mathrm{Na}-\mathrm{Mt}$, the whole zwitterionic SMX is adsorbed which was also observed in the case of AMX, where the adsorbed amount reached a value of about $9.29 \times$ $10^{-4} \mathrm{~mol} \mathrm{~g}^{-1}$. In addition to the diversity in both their moieties and molecular size, probably, the main difference between these two pharmaceuticals remains in the balance change between the zwitterionic and anionic forms which considerably impact the resulting adsorbed amounts leading nevertheless to the intercalation of the pharmaceuticals within the interlayer space of Na-Mt (XRD data not shown). Similar processes 


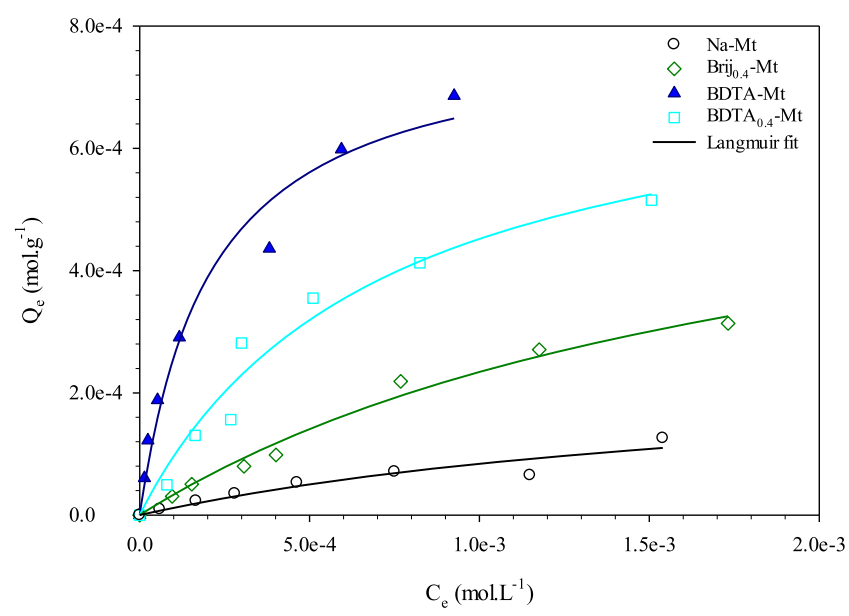

Figure 9. Equilibrium adsorption isotherms of sulfamethoxazole (SMX) onto untreated $\mathrm{Na}$ exchanged montmorillonite: $\mathrm{Na}-\mathrm{Mt}$ (white circle), $\mathrm{BDTA}_{0.4}-\mathrm{Mt}$ (white-filled light blue square), BDTA-Mt (navy blue triangle top) cationic organoclays, and Brijo.4-Mt (white-filled green diamond) nonionic organoclay. The solid lines represent the fits by using the Langmuir equation model.

occur for organoclays $\left(\mathrm{Brij}_{0.4}-\mathrm{Mt}\right.$ and $\left.\mathrm{BDTA}_{0.4}-\mathrm{Mt}\right)$ able to mobilize their inorganic cations in addition to a hydrophobic environment that enhances particularly the adsorption of SMX in both zwitterionic and anionic forms reaching adsorbed amounts of $6.97 \times 10^{-4}$ and $7.71 \times 10^{-4} \mathrm{~mol} \mathrm{~g}^{-1}$ for Brij $\mathrm{B}_{0.4} \mathrm{Mt}$ and $\mathrm{BDTA}_{0.4}-\mathrm{Mt}$, respectively (Table 1). Finally, as explained in the frame of AMX adsorption, BDTA-Mt with its slight excess of cationic charges strongly improves the adsorption with almost a total confinement of SMX within the hydrophobic brush generated by the long alkyl chains of grafted $\mathrm{BDTA}^{+}$in the internal structure of the organoclay (similar FTIR observations as the adsorption of AMX, data not shown).

3.3.3. Adsorption of the Trimethoprim. If both SMX and AMX show trends and affinities similar to organoclays due probably to similar zwitterionic-anionic couples with however a different ratio between these species, TRI radically differs showing mainly cations in solution at a $\mathrm{pH}$ of 6.5 (Figure 2). ${ }^{7,8}$ Thus, the resulting adsorption isotherms at the equilibrium display different line shapes than those previously observed for both SMX and AMX, with the distinction of two main regimes: (i) a gradual growth of the adsorbed amount and (ii) a steady state at high equilibrium concentration (Figure 10). Besides showing a more pronounced hydrophobic character, it appears that it is principally the charge of the pharmaceutical that drives to the adsorption. Thus, with about $80 \%$ TRI cationic species, the adsorption is particularly enhanced onto the phyllosilicate sheets of $\mathrm{Na}-\mathrm{Mt}$ with a maximum adsorbed amount standing at $3.80 \times 10^{-4} \mathrm{~mol} \mathrm{~g}^{-1}$ (half of the CEC value), underlining its intercalation through cation exchange within the interlayer (confirmed by XRD-data not shown). ${ }^{9,8}$ Because both $\mathrm{BDTA}_{0.4}-\mathrm{Mt}$ and $\mathrm{Brij}_{0.4}-\mathrm{Mt}$ showing a dual hydrophobic/hydrophilic behavior and thus providing diverse adsorption sites including the possibility to perform some cation exchanges which is more probably exacerbated in the case of nonionic organoclay, ${ }^{24}$ TRI reaches a maximum adsorbed amount of about $3-4 \times 10^{-4} \mathrm{~mol} \mathrm{~g}^{-1}$, equivalent as Na-Mt. Nevertheless, the nonionic organoclay appears here to be the most efficient sorbent because it offers a good compromise between the preservation of the adsorption sites

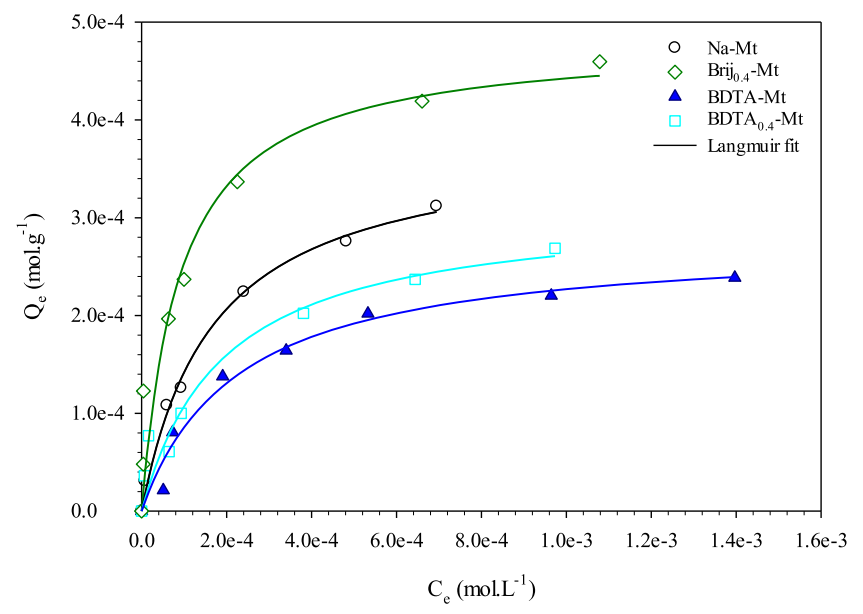

Figure 10. Equilibrium adsorption isotherms of trimethoprim (TRI) onto untreated $\mathrm{Na}$ exchanged montmorillonite: $\mathrm{Na}-\mathrm{Mt}$ (white circle), BDTA $_{0.4}$-Mt (white-filled light blue square), BDTA-Mt (navy blue triangle top) cationic organoclays, and $\mathrm{Brij}_{0.4} \mathrm{-Mt}$ (white-filled green diamond) nonionic organoclay. The solid lines represent the fits by using the Langmuir equation model.

for cation exchange and the hydrophobic environment generated by the presence of surfactants that here enhances the adsorption besides possible steric hindrance that may limit the diffusion of the hydrophobic pharmaceutical. As already observed, cationic organoclays (organophilic ones prepared with long alkyl chains above 1 CEC) and thus including BDTA-Mt show their limits for the adsorption of cationic compounds such as TRI, besides its large $\log P$ which in this case is essentially trapped in its zwitterionic form through molecular hydrophobic and $\pi-\pi$ interactions and thus its mass transfer at about $2.59 \times 10^{-4} \mathrm{~mol} \mathrm{~g}^{-1}$.

3.4. Competitive Adsorption of the Antibiotics on the Layered Materials. Thus, from all of the results, it appears that the electrical charge of the pharmaceuticals mainly governs the degree of adsorption and the hydrophobic character plays a second role. By comparing the parameters derived from the fitting procedure and, in particular, those of the Freundlich model which takes into account the adsorption on heterogeneous surfaces (which is the case here with layered materials showing various adsorption sites) in which the interaction between the antibiotics and the mineral surface is not restricted to the formation of a monolayer, one can estimate precisely the affinity for each organic compound/ layered material couple. More precisely, the Freundlich constant $K_{\mathrm{F}}$ determined with the fitting procedure, where $r^{2}$ $>0.936$ (Table 1) attesting the good agreement of the experimental data, assesses the ability of a material to reduce an amount of pollutants per gram of the adsorbent used or represent the affinity of the compounds with a material. For both AMX and SMX, the $K_{\mathrm{F}}$ ranking highlights the interests of both the cationic and nonionic organoclays (Table 1). Indeed, $K_{\mathrm{F}}$ reaches 0.122 and $0.0785 \mathrm{~L} \mathrm{~mol}^{-1}$ for BDTA-Mt and $\mathrm{Brij}_{0.4^{-}}$ $\mathrm{Mt}$, respectively, for AMX, 1 order of magnitude lower nevertheless to those related to biochar, activated carbon, and even organoclays in the literature. ${ }^{6,10,17,29}$ In these previous studies where the investigated materials were suggested as possible solution for the treatment of water, the studied AMX concentration range was much shorter and, interestingly, a steady state was reached in contrast to the study here where no plateau is observed and the adsorbed amount is nevertheless 
10 times larger. Nevertheless, this study points out the particular affinity of organoclays for zwitterionic compounds, and the nonionic organoclay appears to be the most polyvalent layered material because of its singular ability to perform cation exchanges while involving hydrophobic interaction in the adsorption. $^{24}$

Numerous works focused their efforts on the understanding of the adsorption mechanisms of a pool of different organic pollutants (cocktail) in the natural sample with both natural and synthetic materials for an environmental purpose, without any control of the parameters that may influence the sorption. ${ }^{1,3,12,13}$ Thus, such chemical engineering approach leads to an assessment of the efficiency about the use of materials as sorbents without giving any precise information's about the processes governing the adsorption of each pollutants. ${ }^{3,13}$ In contrast, in this study, the whole parameters (or degrees of freedom) are fixed as well as the knowledge of the organic compounds and the resulting interaction mechanisms leading to the adsorption which represents the first step before to think to work on complex mixtures where antagonist effects may occur and complicate the interpretation of the data. In order to probe an effect of a competition, the use of HPLC coupled to MS was necessary. ${ }^{3,13}$ The experiments with a pool of pharmaceuticals consisted to get equilibrium adsorption isotherms, as obtained for individual antibiotics over nevertheless a restricted concentration range with a special care to avoid any precipitation and by fixing for each measurement the same starting concentration for every compounds. With these experiments, several issues were raised including: (i) the ability of different materials to adsorb the totality of the antibiotics and in which extent; (ii) the possibility of a release; (iii) the possible association of antibiotics which may enhance to or limit the adsorption; and (iv) the fate of a pool of organic compounds with a clay mineral that can, after being in contact, form an organoclay (different to hybrid materials prepared with surfactants), of which the chemicals by lining its surface can facilitate subsequently further adsorption.

The resulting adsorption isotherms, in particular those relative to the $\mathrm{Brij}_{0.4}-\mathrm{Mt}$, confirm the affinity of the whole antibiotics toward the layered materials, which seem to offer sufficient sites to completely adsorb the pharmaceuticals with nevertheless the observation of a plateau (Figure 11, see Figures SI-4 and SI-5 for the adsorption isotherms of the antibiotics onto $\mathrm{Na}-\mathrm{Mt}$ and BDTA-Mt). Here, the saturation of the adsorption can be related to a competition effect of the species for the different adsorption sites thus limiting their mass transfer onto the layered materials which, indeed, differs from the individual adsorption isotherms of AMX and SMX (Figures 4 and 9) displaying no steady state. However, the line shapes of the isotherms mainly depend on the type of layered materials as well as the nature of the antibiotics where the saturation is not reached for SMX on BDTA-Mt for instance. As it was observed for the individual adsorption of the antibiotics where the nonionic organoclay appears to be the most versatile material, the same observation occurs in the context of a pool of pharmaceuticals, where here consists of a mixture of cations (TRI), anions (SMX and AMX), and zwitterions (AMX, SMX, and TRI). Indeed, the sum of the adsorbed amounts of all of the antibiotics reaches $4.8 \times 10^{-4}$, $3.6 \times 10^{-4}$, and $3.4 \times 10^{-4} \mathrm{~mol} \mathrm{~g}^{-1}$ for $\mathrm{Brij}_{0.4} \mathrm{Mt}, \mathrm{Na}-\mathrm{Mt}$, and BDTA-Mt, respectively, underlining if one uses the total adsorbed quantity as a parameter to list the layered materials,

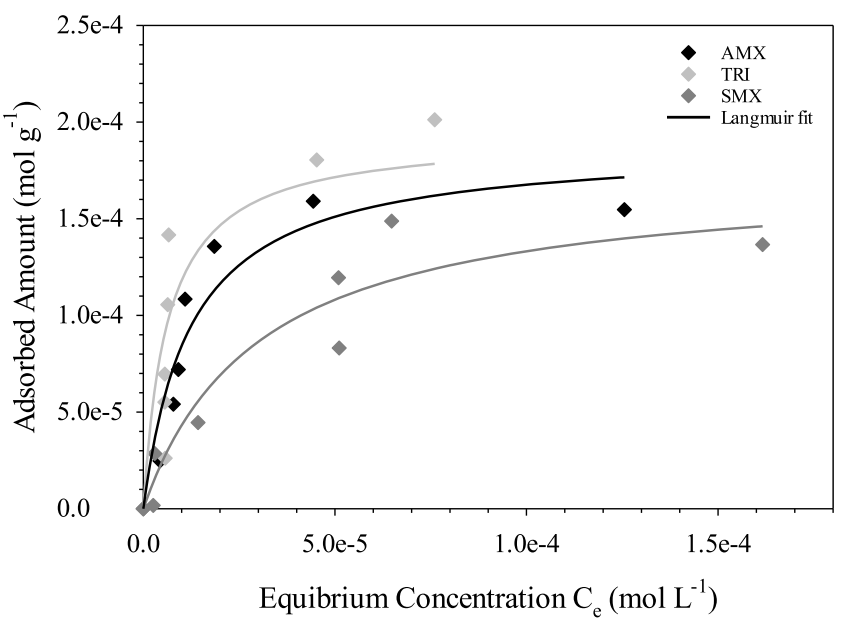

Figure 11. Equilibrium adsorption isotherms of a pool of antibiotics: amoxicillin (AMX) in black circle, sulfamethoxazole (SMX) in dark gray circle, and trimethoprim (TRI) in light gray circle onto Brij ${ }_{0.4}-\mathrm{Mt}$ organoclay (other data related of the adsorption of a pool of PP onto Na-Mt and BDTA-Mt are shown in the Supporting Information). The solid lines represent the fits by using the Langmuir equation model.

the efficiency of the nonionic organoclay. Interestingly, the cationic organoclay which appeared previously in the individual adsorption as an efficient material to uptake the pollutants suffers from a competition effect that limits considerably the adsorbed amounts (Figure SI-5). In contrast, the adsorption appears to be enhanced on Na-Mt once in contact with numerous compounds where probably the adsorption of some pharmaceuticals modifies the nature of the mineral surface leading to an improvement of further molecules (Figure SI-4). However, besides some adsorption kinetical experiments were performed, it was rather hard to precisely determine the nature of the antibiotics adsorbed in the first step (if TRI as a cationic compound was adsorbed primarily for instance), or probably the adsorption results here to a combination of organic compounds on a mineral phase showing a large number of accessible sites. This requires additional experiments and will be investigated in the next future work.

If the maximal adsorbed amount can be used as a pertinent parameter to compare the efficiency of the layered materials on the same concentration range, it is not relevant for the estimation of a change of affinity (i.e., between mineral phases and the pharmaceuticals) in the case of a pool of antibiotics (where the concentration range differed). $K_{\mathrm{F}}$, already used to discuss the adsorption capacity of the layered materials to literature data, expresses a real contrast regarding the degree of adsorption toward each antibiotic in a situation of mixing. Despite the versatility of the interaction mechanisms implied with $\mathrm{AMX},{ }^{6,10,17,29}$ this zwitterion compound appears to suffer the most from the competition with the two other antibiotics. Indeed, the resulting $K_{\mathrm{F}}$ constants are much smaller than those previously determined when AMX was individually adsorbed on the layered materials (Table 1). In contrast, both TRI and SMX antibiotics seem to take advantage or benefit of the competition because their $K_{\mathrm{F}}$ constants increase of several percent from 23 to $147 \%$ (except that one of TRI with BDTA$\mathrm{Mt}$, which is not a surprise and quite logic with regards to the absence of adsorption sites in BDTA-Mt for cationic compounds). Such difference behavior among the antibiotics is quite interesting because it was expected to get a decrease of 
the affinity for the whole investigated antibiotics which can also be determined by the removal percentages (Table 2). AMX,

Table 2. Removal Percentages of the Different Antibiotics: AMX, SMX, and TRI by Na-Mt, BDTA . $_{0.4}$ Mt, BDTA-Mt, and $\mathrm{Brij}_{0.4}$-Mt in Individual and Mixing (Pool) Conditions

\begin{tabular}{cccc} 
analytes at $\left(2 \times 10^{-4} \mathrm{~mol} \cdot \mathrm{L}^{-1}\right)$ & $\begin{array}{c}\text { Na-Mt } \\
(\%)\end{array}$ & $\begin{array}{c}\text { BDTA-Mt } \\
(\%)\end{array}$ & $\begin{array}{c}\text { Brij } \\
(\%)\end{array}$ \\
AMX & 52.77 & 82.42 & 68.25 \\
pool & 70.90 & 22.79 & 90.73 \\
SMX & 16.33 & 91.07 & 95.35 \\
pool & 74.14 & 80.96 & 96.69 \\
TRI & 65.76 & 68.99 & 98.39 \\
pool & 83.98 & 50.81 & 74.53 \\
\hline
\end{tabular}

with its extreme versatility, was easily adsorbed on every different layered materials without the presence of other molecules but suffer from molecules of which bold electric charge once mixed all together and in competition to the adsorption onto the layered materials (Figure 12). The introduction of bold electric charged molecules such as SMX and TRI may play the role of electrolytes, disrupting strongly the interactional mechanisms leading to the decrease of the adsorption of AMX (Tables 1 and 2). In contrast, interestingly, TRI and SMX benefit from the competition effect by showing an improvement of their affinity to every adsorbents which can be explained through a possible combination of these two species in solution. ${ }^{8,20}$ Indeed, it is important to mention that these two compounds are often administered in tandem that can find a meaning beyond the therapeutical aspect through their possible ionic combination facilitating then their assimilation within the carrier mineral phases.

\section{CONCLUSIONS}

The understanding of the interactional mechanisms leading to the adsorption of pharmaceuticals defined recently as emerging pollutants (because these organics are massively administered with the growth of the aging population in our modern societies which thus represent a serious concern) on both untreated and modified by surfactants (organoclays) clay minerals can give important insights into the development of novel sorbents for environmental issues (water treatment). It also concerns the fate of pollutants associated with mineral phases where the stability of the organo-mineral complexes depends on the resulting forces between adsorbent and analytes that can fluctuate, driving to a release of the confined or adsorbed pollutants with a change of the experimental conditions.

In this study, we focused on the adsorption of three antibiotics, showing different electric charges and quite complex species with functional groups as diverse as their therapeutic uses, on four layered materials based on a clay mineral that can play the role of holding phases of pollutants that can be easily released following the experimental conditions. With the set of complementary data, it appears that the electric charge mainly controls the adsorption and the hydrophobic behavior plays a second role but seems to improve the adsorbed amounts. In particular, the nonionic organoclay demonstrates again its versatility in the adsorption in both individual adsorption and in mixing conditions where competition between antibiotics was expected. Mixing three antibiotics allowed us to simply mimic the natural context, where the mineral phases are often in contact with a cocktail of pollutants (or organic matter), amplifying their toxicity, but where the competition significantly perturbs the adsorption behavior of the species (in contrast to the individual situation). This competition leads to a decrease of the affinity of the AMX in the presence of other molecules (or electrolytes) where however its zwitterion feature allows an easy adsorption on the whole materials in large amounts. In contrast, both SMX and TRI once mixed are easily adsorbed. This surprising observation of the enhancement of the adsorption of TRI and SMX may be related to a possible association of these two species adding a synergistic effect, important to be taken into account in the natural context where such phenomenon is

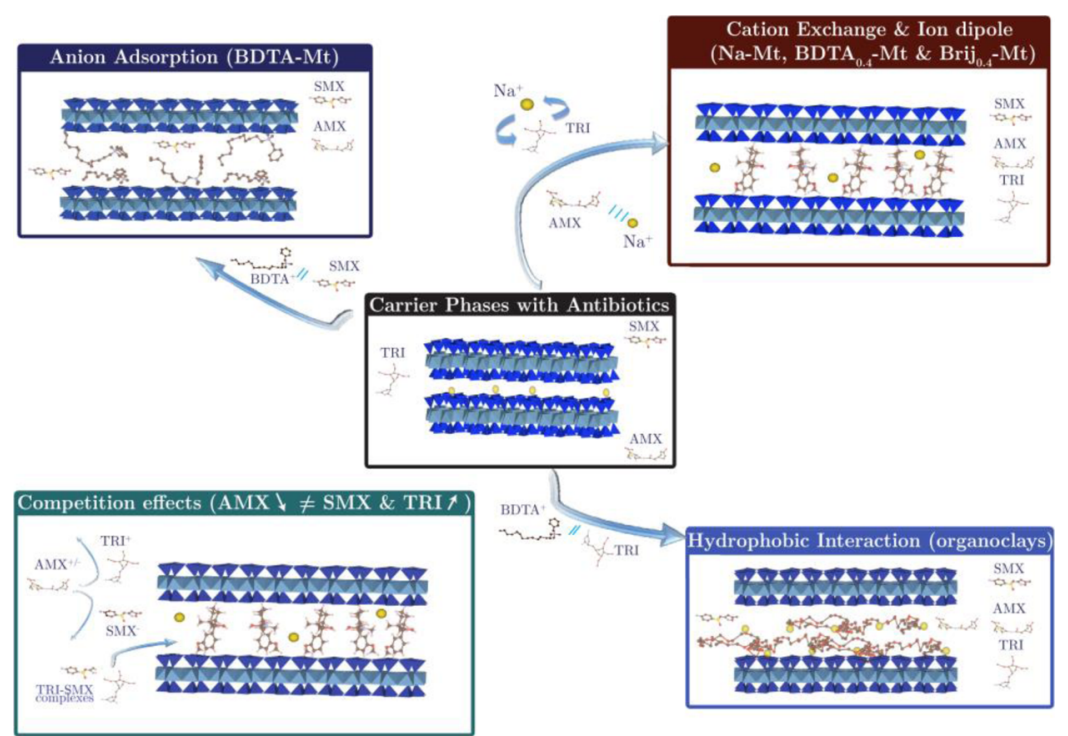

Figure 12. Schematic representation of the possible interaction mechanisms leading to the adsorption of the antibiotics: AMX, SMX, and TRI onto $\mathrm{Na}-\mathrm{Mt}, \mathrm{Brij}_{0.4}-\mathrm{Mt}, \mathrm{BDTA}_{0.4}-\mathrm{Mt}$, and BDTA-Mt. In the case of a pool of pharmaceuticals, it leads to a decrease of the affinity of AMX with the whole studied layered materials because of the presence of electrolytes: bold charged SMX and TRI molecules which show an enhancement of the adsorption, probably due to their possible association. 
surely transposable and observable but requires further experiments with additional molecules in competition to properly highlight it.

\section{ASSOCIATED CONTENT}

\section{S Supporting Information}

The Supporting Information is available free of charge on the ACS Publications website at DOI: 10.1021/acsomega.8b02049.

XRD patterns for dehydrated Na-Mt, BDTA0.4-Mt, BDTA-Mt, and Brij0.4-Mt organoclays; FTIR spectra of dehydrated Na-Mt, BDTA0.4-Mt, BDTA-Mt, and Brij0.4-Mt organoclays; 3D evolution of the FTIR spectra; and equilibrium adsorption isotherms of a pool of antibioticsPDF

\section{AUTHOR INFORMATION}

\section{Corresponding Author}

*E-mail: regis.guegan@univ-orleans.fr, regis.guegan@aoni. waseda.jp.

ORCID $\odot$

Yoshiyuki Sugahara: 0000-0003-2973-8052

Régis Guégan: 0000-0002-8152-6826

Notes

The authors declare no competing financial interest.

\section{REFERENCES}

(1) Li, B.; Zhang, T. Biodegradation and Adsorption of Antibiotics in the Activated Sludge Process. Environ. Sci. Technol. 2010, 44, 3468-3473.

(2) Meng, X.-Z.; Venkatesan, A. K.; Ni, Y.-L.; Steele, J. C.; Wu, L.-L.; Bignert, A.; Bergman, Å.; Halden, R. U. Organic Contaminants in Chinese Sewage Sludge: A Meta-Analysis of the Literature of the Past 30 Years. Environ. Sci. Technol. 2016, 50, 5454-5466.

(3) Thiebault, T.; Boussafir, M.; Le Forestier, L.; Le Milbeau, C.; Monnin, L.; Guégan, R. Competitive adsorption of a pool of pharmaceuticals onto a raw clay mineral. RSC Adv. 2016, 6, 6525765265 .

(4) Tolls, J. Sorption of Veterinary Pharmaceuticals in Soils: A Review. Environ. Sci. Technol. 2001, 35, 3397-3406.

(5) Watkinson, A. J.; Murby, E. J.; Costanzo, S. D. Removal of antibiotics in conventional and advanced wastewater treatment: Implications for environmental discharge and wastewater recycling. Water Res. 2007, 41, 4164-4176.

(6) Adriano, W. S.; Veredas, V.; Santana, C. C.; Gonçalves, L. R. B. Adsorption of amoxicillin on chitosan beads: Kinetics, equilibrium and validation of finite bath models. Biochem. Eng. J. 2005, 27, 132137.

(7) Bekci, Z.; Seki, Y.; Yurdakoc, M. Equilibrium studies for trimethoprim adsorption on montmorillonite KSF. J. Hazard. Mater. 2006, 133, 233-242.

(8) Nielsen, L.; Bandosz, T. J. Analysis of sulfamethoxazole and trimethoprim adsorption on sewage sludge and fish waste derived adsorbents. Microporous Mesoporous Mater. 2016, 220, 58-72.

(9) Park, Y.; Ayoko, G. A.; Frost, R. L. Application of organoclays for the adsorption of recalcitrant organic molecules from aqueous media. J. Colloid Interface Sci. 2011, 354, 292-305.

(10) Pouretedal, H. R.; Sadegh, N. Effective removal of Amoxicillin, Cephalexin, Tetracycline and Penicillin G from aqueous solutions using activated carbon nanoparticles prepared from vine wood. $J$. Water Process Eng. 2014, 1, 64-73.

(11) Putra, E. K.; Pranowo, R.; Sunarso, J.; Indraswati, N.; Ismadji, $S$. Performance of activated carbon and bentonite for adsorption of amoxicillin from wastewater: Mechanisms, isotherms and kinetics. Water Res. 2009, 43, 2419-2430.
(12) Rakić, V.; Rac, V.; Krmar, M.; Otman, O.; Auroux, A. The adsorption of pharmaceutically active compounds from aqueous solutions onto activated carbons. J. Hazard. Mater. 2015, 282, 141149

(13) Thiebault, T.; Boussafir, M.; Guégan, R.; Le Milbeau, C.; Le Forestier, L. Clayey-sand filter for the removal of pharmaceuticals from wastewater effluent: percolation experiments. Environ. Sci.: Water Res. Technol. 2016, 2, 529-538.

(14) Thiebault, T.; Guégan, R.; Boussafir, M. Adsorption mechanisms of emerging micro-pollutants with a clay mineral: Case of tramadol and doxepine pharmaceutical products. J. Colloid Interface Sci. 2015, 453, 1-8.

(15) Thiele-Bruhn, S.; Seibicke, T.; Schulten, H.-R.; Leinweber, P. Sorption of Sulfonamide Pharmaceutical Antibiotics on Whole Soils and Particle-Size Fractions. J. Environ. Qual. 2004, 33, 1331-1342.

(16) Yao, Y.; Gao, B.; Chen, H.; Jiang, L.; Inyang, M.; Zimmerman, A. R.; Cao, X.; Yang, L.; Xue, Y.; Li, H. Adsorption of sulfamethoxazole on biochar and its impact on reclaimed water irrigation. J. Hazard. Mater. 2012, 209-210, 408-413.

(17) Zha, S.; Zhou, Y.; Jin, X.; Chen, Z. The removal of amoxicillin from wastewater using organobentonite. J. Environ. Manage. 2013, $129,569-576$.

(18) Zhang, D.; Pan, B.; Zhang, H.; Ning, P.; Xing, B. Contribution of Different Sulfamethoxazole Species to Their Overall Adsorption on Functionalized Carbon Nanotubes. Environ. Sci. Technol. 2010, 44, 3806-3811.

(19) Rebhun, M.; Kalabo, R.; Grossman, L.; Manka, J.; Rav-Acha, C. Sorption of organics on clay and synthetic humic-clay complexes simulating aquifer processes. Water Res. 1992, 26, 79-84.

(20) De Oliveira, T.; Guégan, R. Coupled Organoclay/Micelle Action for the Adsorption of Diclofenac. Environ. Sci. Technol. 2016, 50, 10209-10215.

(21) De Oliveira, T.; Guégan, R.; Thiebault, T.; Milbeau, C. L.; Muller, F.; Teixeira, V.; Giovanela, M.; Boussafir, M. Adsorption of diclofenac onto organoclays: Effects of surfactant and environmental ( $\mathrm{pH}$ and temperature) conditions. J. Hazard. Mater. 2017, 323, 558566.

(22) Guégan, R. Self-assembly of a non-ionic surfactant onto a clay mineral for the preparation of hybrid layered materials. Soft Matter 2013, 9, 10913-10920.

(23) Guégan, R. Intercalation of a Nonionic Surfactant (C10E3) Bilayer into a Na-Montmorillonite Clay. Langmuir 2010, 26, 1917519180.

(24) Guégan, R.; Giovanela, M.; Warmont, F.; Motelica-Heino, M. Nonionic organoclay: A 'Swiss Army knife' for the adsorption of organic micro-pollutants? J. Colloid Interface Sci. 2015, 437, 71-79.

(25) Guégan, R.; Sueyoshi, K.; Anraku, S.; Yamamoto, S.; Miyamoto, N. Sandwich organization of non-ionic surfactant liquid crystalline phases as induced by large inorganic $\mathrm{K} 4 \mathrm{Nb} 6 \mathrm{O} 17$ nanosheets. Chem. Commun. 2016, 52, 1594-1597.

(26) Guégan, R.; Veron, E.; Le Forestier, L.; Ogawa, M.; Cadars, S. Structure and Dynamics of Nonionic Surfactant Aggregates in Layered Materials. Langmuir 2017, 33, 9759-9771.

(27) Lee, Y.-C.; Park, W.-K.; Yang, J.-W. Removal of anionic metals by amino-organoclay for water treatment. J. Hazard. Mater. 2011, 190, $652-658$.

(28) Crea, F.; Cucinotta, D.; De Stefano, C.; Milea, D.; Sammartano, S.; Vianelli, G. Modeling solubility, acid-base properties and activity coefficients of amoxicillin, ampicillin and (+)6-aminopenicillanic acid, in $\mathrm{NaCl}(\mathrm{aq})$ at different ionic strengths and temperatures. Eur. J. Pharm. Sci. 2012, 47, 661-677.

(29) Ghauch, A.; Tuqan, A.; Assi, H. A. Antibiotic removal from water: Elimination of amoxicillin and ampicillin by microscale and nanoscale iron particles. Environ. Pollut. 2009, 157, 1626-1635.

(30) Bebu, A.; Szabó, L.; Leopold, N.; Berindean, C.; David, L. IR, Raman, SERS and DFT study of amoxicillin. J. Mol. Struct. 2011, 993, $52-56$. 